\title{
Distribution of Malocclusion and Occlusal Traits among Tibetan Adolescents residing in Nepal
}

Dr Saujanya Karki,' Dr Umesh Parajuli,2 Dr Nischal Kunwar, ${ }^{3}$ Dr Kunsang Namgyal,, Dr Khamsum Wangdu ${ }^{5}$ 'Dept of Community \& Public Health Dentistry, Dhulikhel Hospital, Dhulikhel, Nepal ${ }^{2}$ Assistant Professor, Dept of Dentistry, Gandaki Medical College, Pokhara, Nepal 3.4.5Intern, Kantipur Dental College, Kathmandu, Nepal

Correspondence: Dr Saujanya Karki; email: dr.saujanyakarki@yahoo.com

\section{ABSTRACT}

Introduction: Malocclusion is the irregularity of teeth and is considered as oral health problem. Though etiology of malocclusion is multifactorial, it has considerable impact on the self esteem and social adjustment of an individual.

Objective: To determine the prevalence of malocclusion and to assess the association between Angle classification of malocclusion and occlusal traits.

Materials \& Method: A cross sectional study was conducted among 138 Tibetan students of grade 8-12 were selected. Students with history of orthodontic treatment were excluded from the study. Data was recorded and analyzed using SPSS 17.0 and chi square test was used to evaluate the association between Angle classification of malocclusion and occlusal traits.

Result: The prevalence of malocclusion was found to be Angle's Class I (52.90\%), Angle's Class II (5.10\%) and Angle's Class III (9.40\%). Occlusal traits such as overbite, increased overjet, openbite, crossbite, displacement and hypodontia was found to be $5.79 \%, 10.8 \%, 10.86 \%, 9.42 \%, 50,72 \%$ and $4.34 \%$ respectively.

Conclusion: The prevalence of malocclusion among Tibetan adolescent was found to be higher. Hence, oral health awareness, preventive procedures and promotional programs need to be more emphasized.

Keywords: adolescent, Angle classification, malocclusion

\section{INTRODUCTION}

The normal occlusion defined by Angle was that the mesiobuccal cusp of the upper first molar should occlude in the buccal groove of the lower first molar and teeth were arranged on a smoothly curving line of occlusion.' Dental occlusion may vary among individuals, age, race, gender and ethnic group. It may be as a result of variation in tooth size and shape, tooth position, sequence and timing of eruption, shape and size of dental arch and pattern of craniofacial growth. ${ }^{2,3}$

Malocclusal is not a disease but a developmental anomaly of teeth and/or dental arch resulting from various etiological factors causing esthetic dissatisfaction to functional impartment and even disability. ${ }^{4.5}$ Malocclusion has been affecting on people physiologically and psychologically as a consequent it has impact on their quality of life and well-being. ${ }^{6,7}$ Beside, it has been adding economic burden as orthodontic treatment is considered as one of the expensive oral health problem to treat. According to World Health Organization (WHO), malocclusion occurs in majority of the population and it is considered as one of the major oral health problem. ${ }^{7}$

Various epidemiological studies have been conducted worldwide to assess the prevalence of malocclusion and to describe the occlusal trait. ${ }^{8-12}$ In this context, very few studies have been conducted in Tibetan population. Thus, this study was conducted to assess the prevalence of malocclusion and occlusal traits in Tibetan adolescents.

\section{MATERIALS AND METHOD}

A cross sectional study was conducted among the Tibetan students studying in grade 8-12 of SOS Hermann Gmeinier Higher Secondary School, Pokhara. This study was conducted after obtaining ethical approval from the Institutional Review Committee, Kantipur Dental College Teaching Hospital and Research Center.

A total of 138 students with no history of orthodontic treatment were examined after obtaining permission from the concern authorities and along with the consent of school principal and students. All the examinations were 
carried out by four trained dentists under the supervision of an Orthodontist. The examination was done in the school recreation hall on wooden chairs under adequate daylight with the help of mouth mirror, dental explorer, pencil, stainless steel millimeter scale and divider and maximum aseptic environment was maintained.

The data was recorded and analyzed using SPSS version 17.0. The descriptive statistics was assessed and the association between Angle's classification of malocclusion and occlusal traits were assessed using chi-square test $(p<0.05)$.

\section{Variables in the study:}

Molar Relationship: The relationship between upper and lower first permanent molars were used to determine Angle's Class I, Class II or Class III malocclusions.

Overbite: Measurements between 0 to $3.4 \mathrm{~mm}$ were considered normal, while the other categories includes; increased overbite greater than or equal to $3.5 \mathrm{~mm}$ without gingival trauma, complete overbite without gingival or palatal trauma and complete overbite with gingival or palatal trauma.

Overjet: Measurements between 0 to $3.4 \mathrm{~mm}$ were considered normal, while the other categories of increased overjet includes; greater than $3.5 \mathrm{~mm}$ but less than or equal to $6 \mathrm{~mm}$, greater than $6 \mathrm{~mm}$ but less than or equal to $9 \mathrm{~mm}$ and greater than $9 \mathrm{~mm}$.

Openbite (Anterior): Open bite in anterior region greater than $1 \mathrm{~mm}$ but less than or equal to $2 \mathrm{~mm}$ were considered as anterior openbite and other categories includes; open bite greater than $2 \mathrm{~mm}$ but less than or equal to $4 \mathrm{~mm}$ and open bite greater than $4 \mathrm{~mm}$.

Crossbite (Anterior): When there was a crossover of at least one tooth in the anterior region of the dental arch were considered as anterior crossbite. Categories includes; crossbite with less than or equal to $1 \mathrm{~mm}$ discrepancy, crossbite with greater than $1 \mathrm{~mm}$ but less than or equal to
$2 \mathrm{~mm}$ discrepancy and crossbite with greater than $2 \mathrm{~mm}$ discrepancy.

Displacement: Displacement is the distance between the natural contact points of the adjacent teeth; which is not a measure of crowding. Measurements 0 to $1 \mathrm{~mm}$ were considered normal, while other categories are; displacement of teeth greater than $1 \mathrm{~mm}$ but less than or equal to $2 \mathrm{~mm}$, displacement of teeth greater than $2 \mathrm{~mm}$ but less than or equal to $4 \mathrm{~mm}$ and severe displacements of teeth greater than $4 \mathrm{~mm}$.

Hypodontia: Hypodontia/missing space requiring prerestorative orthodontics or orthodontic space closure to omit the need for prosthesis were considered as less extensive while need of prosthesis of more than one tooth missing in any quadrant requiring pre-restorative orthodontics were considered as extensive hypodontia.

\section{RESULT}

A total of 138 Tibetan students were examined among which 78 were female and 60 were male. The study showed that $32.60 \%$ had normal occlusion where as the prevalence of malocclusion were Angle's Class I (52.90\%), Angle's Class II (5.10\%), and Angle's Class III (9.40\%) respectively (Figure 1).

The present study showed that $5.79 \%$ had increased overbite while $10.8 \%$ had increased overjet. It was also observed that $10.86 \%$ had openbite, $9.42 \%$ had crossbite, $50.72 \%$ had displacement and hypodontia was seen in $4.34 \%$ respectively (Table 1 ). The present study revealed that there was statistical significant association between overbite, overjet, crossbite (anterior), hypodontia and Angle classification of malocclusion $(p<0.05)$. It also revealed that there was statistically significant association between displacement and Angle classification of malocclusion $(p<0.05)$. The present study showed that the association between openbite (anterior) and Angle classification of malocclusion were not statistically significant $(p<0.05)$.

Figure 1: Distribution of students according to Angle Classification of malocclusion

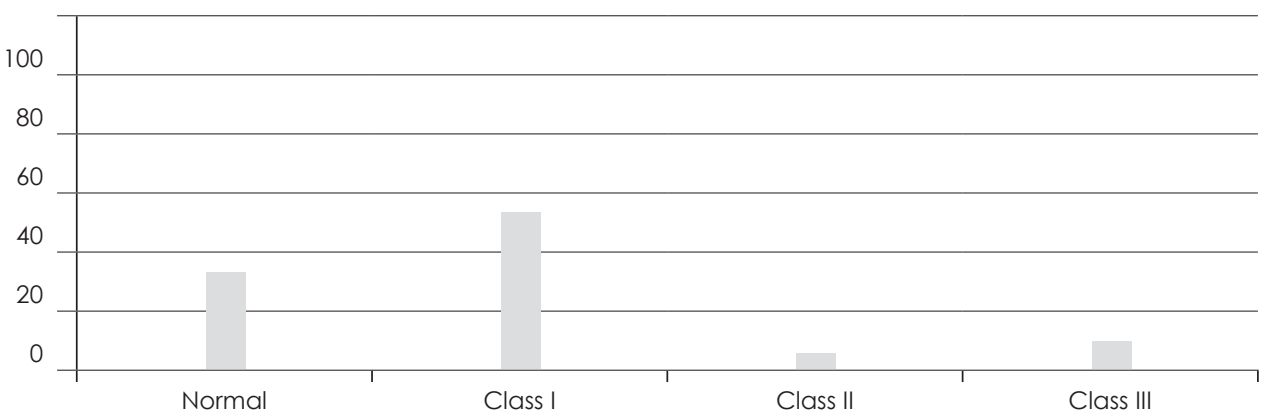


Table 1: Distribution of occlusal traits and their association with Angle classification of malocclusion

\begin{tabular}{|c|c|c|c|c|c|c|}
\hline \multicolumn{2}{|r|}{ Angle Classification } & $\begin{array}{l}\text { Normal } \\
(\mathrm{N}=45)\end{array}$ & $\begin{array}{l}\text { Class I } \\
(\mathrm{N}=73)\end{array}$ & $\begin{array}{l}\text { Class II } \\
(\mathrm{N}=7)\end{array}$ & $\begin{array}{l}\text { Class III } \\
(\mathrm{N}=13)\end{array}$ & $p$-value \\
\hline \multirow{4}{*}{ Overbite } & Normal & 45 & 55 & 6 & 9 & \multirow{4}{*}{$0.043^{*}$} \\
\hline & $\geq 3.5 \mathrm{~mm}$ (without gingival contact) & - & 8 & - & - & \\
\hline & Complete (w/o gingival trauma) & - & - & - & - & \\
\hline & Complete (with gingival trauma) & - & - & - & - & \\
\hline \multirow{4}{*}{ Overjet } & Normal & 45 & 54 & 4 & 8 & \multirow{4}{*}{$0.010^{*}$} \\
\hline & $>3.5 \mathrm{~mm}$ to $\leq 6 \mathrm{~mm}$ & - & 11 & 3 & - & \\
\hline & $>6 \mathrm{~mm}$ to $\leq 9 \mathrm{~mm}$ & - & 1 & - & - & \\
\hline & $>9 \mathrm{~mm}$ & - & - & - & - & \\
\hline \multirow{4}{*}{$\begin{array}{l}\text { Open bite } \\
\text { (Anterior) }\end{array}$} & Normal & 45 & 55 & 6 & 9 & \multirow{4}{*}{0.134} \\
\hline & $>1 \mathrm{~mm}$ to $\leq 2 \mathrm{~mm}$ & - & 4 & - & 1 & \\
\hline & $>2 \mathrm{~mm}$ to $\leq 4 \mathrm{~mm}$ & - & 2 & - & 1 & \\
\hline & $>4 \mathrm{~mm}$ & - & 4 & 1 & 2 & \\
\hline \multirow{4}{*}{$\begin{array}{l}\text { Crossbite } \\
\text { (Anterior) }\end{array}$} & Normal & 45 & 53 & 4 & 8 & \multirow{4}{*}{$0.005^{*}$} \\
\hline & $\leq 1 \mathrm{~mm}$ & - & 5 & - & 2 & \\
\hline & $1 \mathrm{~mm}$ to $\leq 2 \mathrm{~mm}$ & - & 3 & - & 3 & \\
\hline & $>2 \mathrm{~mm}$ & - & - & - & - & \\
\hline \multirow{4}{*}{ Displacement } & Normal & 45 & 17 & 1 & 5 & \multirow{4}{*}{$0.000^{*}$} \\
\hline & $>1 \mathrm{~mm}$ to $\leq 2 \mathrm{~mm}$ & - & 22 & 2 & 3 & \\
\hline & $>2 \mathrm{~mm}$ to $\leq 4 \mathrm{~mm}$ & - & 22 & 2 & 3 & \\
\hline & $>4 \mathrm{~mm}$ & - & 12 & 2 & 2 & \\
\hline \multirow{3}{*}{ Hypodontia } & Normal & 45 & 69 & 7 & 11 & \multirow{3}{*}{$0.022^{*}$} \\
\hline & Less extensive & - & 3 & - & - & \\
\hline & Extensive & - & 1 & - & 2 & \\
\hline
\end{tabular}

*statistically significant $(p<0.05)$

\section{DISCUSSION}

In this present study, the prevalence of Angle's Class I malocclusion was found to be higher which is similar to other studies. ${ }^{13-21}$ The present study showed that the normal occlusion was found to be $32.60 \%$ while the study conducted by Farahani $A B$ et $a^{22}$ found that $22.9 \%$ had normal occlusion similarly Arabiun $\mathrm{H}$ et $\mathrm{a}^{23}$ and Singh VP et $a^{21}$ found that $76.30 \%$ and $14.42 \%$ had normal occlusion respectively. Wada $\mathrm{T}$ et al examined 2000 subjects and found that $3.4 \%$ had class III malocclusion similarly Sharma $\mathrm{JN}$ with sample of 134 found $5.97 \%$, Shrestha BK et al found $16 \%$, Baral $P$ found that $15.6 \%$ among 260 mongoloid patients, Shrestha S et al found $8.40 \%$ and Singh VP found $4.32 \%$ had class III malocclusion where as in this study with sample 138, 9.40\% had class III malocclusion. 13, 14,15,19,20,21

The present study showed that $5.79 \%$ had increased overbite which was similar to the other studies ${ }^{21,24}$ where as it was found to be higher in a study conducted by Ciuffolo $\mathrm{F}$ et al. ${ }^{25}$ With respect to overjet, Tang $\mathrm{EL}^{16}$ found $14.9 \%$ had increased overjet similarly Shrestha $S$ et al, ${ }^{20}$ Singh VP et $a{ }^{2},{ }^{21}$ Farahani $A B$ et $a l,{ }^{22}$ Jamilian $A,{ }^{24}$ Ciuffolo F et $a^{25}$ reported that $43.75 \%, 17.51 \%, 24.5 \%, 22.7 \%$ and $41.0 \%$ had increased overjet respectively which is higher in comparison to the present study. Various studies conducted by Gabris K et al, ${ }^{9}$ Tang EL, ${ }^{16}$ Singh VP et $a l,{ }^{21}$
Farahani $\mathrm{AB}$ et $\mathrm{al},{ }^{22}$ Arabiun $\mathrm{H}$ et $\mathrm{al}^{23}$ Ciuffolo $\mathrm{F}$ et $\mathrm{al}^{25}$ and Aikins EA et $a^{26}$ also reported that $8.9 \%, 1.5 \%, 2.03 \%, 1.6 \%$, $0.82 \%, 1.7 \%$ and $7.1 \%$ had anterior openbite which was comparatively lower than the present study which has $10.86 \%$ openbite. Concerning crossbite, Farahani $A B$ et $a^{22}$ and Baral $P^{19}$ reported that $8.4 \%$ and $10.4 \%$ (among Aryan) had crossbite which was supported by the present study. In a study conducted by Shrestha $S$ et a ${ }^{20}$ on 464 study models reported that $65.73 \%$ had displacement which is higher than the present study.

\section{CONCLUSION}

The result of this study showed that the prevalence of malocclusion among Tibetan Adolescents was found to be higher typically Angle Class I (52.90\%). Occlusal traits such as increased overbite, increased overjet, openbite, crossbite displacement and hypodontia was found to be $5.79 \%, 10.8 \%, 10.86 \%, 9.42 \%, 50,72 \%$ and $4.34 \%$ respectively. The association between overbite, overjet, crossbite (anterior), hypodontia and displacement on Angle classification of malocclusion were found to be statistically significant $(p<0.05)$.

Hence, it can be concluded that more emphasis on oral health awareness, preventive procedures and promotional programs can be advocated to this group. 


\section{ACKNOWLEDGEMENT}

The authors would like to thank Tibetan Family Help Nepal and SOS Hermann Gmeinier Higher Secondary School, Pokhara family for their support and co-operation to conduct this study. The authors would also like to acknowledge the contribution of Dr. Rabindra Man
Shrestha and Dr. Sujita Shrestha for their guidance. Furthermore, we would also like to thank Dr. John Gurung, Kantipur Dental College Teaching Hospital \& Research Center and Kantipur Institute of Health Science, Pokhara for their support.

\section{REFERENCES}

1. Proffit WR, Fields HW, Sarver DM. Contemporary Orthodontics. 4th ed. India: Mosby, Health Science imprints of Elsevier; 2008 : 3-23.

2. Premkumar S. Graber's Textbook of Orthodontics: Basic Principle and Practice. 4th ed. Saunders, Health Science imprints of Elsevier; 2009: 135-54.

3. Hassan R, Rahimah AK. Occlusion, Malocclusion and method of measurement: an overview. Archives of Orofacial Sciences 2007; 2: 3-9.

4. Massuia JM, Carvalho WO. Prevalence and associated factors of malocclusion in the primary dentition. R RGO - Rev Gaúcha Odontol 2012 July-Sept; 60(3): 329-35.

5. Brito DI, Dias PF, Gleiser R. Prevalence of malocclusion in children aged 9 to 12 years old in the city of Nova Friburgo, Rio de Janeiro State, Brazil. R Dental Press Ortodon Ortop Facial 2009 Nov-Dec; 14(6): $118-124$.

6. Sheiham A. Oral health, general health and quality of life. Bulletin of World Health Organization 2005 Sept; 83(9): 644.

7. Petersen PE, Bourgeois D, Ogawa H, Estupinan-Day S, Ndiaye C. The global burden of oral diseases and risks to oral health. Bulletin of World Health Organization 2005 Sept; 83(9): 661-69.

8. Tak M, Nagarajappa R, Sharda AJ, Asawa K, Tak A, Jalihal S, et al Prevalence of malocclusion and orthodontic treatment needs among 12-15 years old school children of Udaipur, India. Eur J Dent 2013; 7: 45-53.

9. Gabris K, Marton S, Madlena M. Prevalence of malocclusions in Hungarian adolescents. European Journal of Orthodontics 2006; 28: 467-70.

10. Claudino D, Traebert J. Malocclusion, dental aesthetic self-perception and quality of life in a 18 to 21 year-old population: a cross sectional study. BMC Oral Health 2013; 13:3.

11. Cavalcanti AL, Santos JA, Aguiar YP, Xavier AF, Moura C. Prevalence and severity of malocclusion in Brazilian adolescents using the dental aesthetic index (DAI). Pakistan Oral \& Dental Journal 2013 Dec; 33(3): 473-79.

12. Moreno NA, Aranza OT. Frequency of malocclusions in association with body posture problems in a school-age population from the state of Mexico. Bol Med Hosp Infant Mex 2013; 70(5): 362-68.

13. Wada T, Mizutani S, Tatsuta U, Shrestha RM. The oral health status of the Kathmandu valley, Nepal: Report of the oral health survey 1997 1999. Osaka University Graduate School of Dentistry. Phect-Nepal. Unpublished Report; 1999.

14. Sharma JN. Epidemiology of malocclusion and assessment of orthodontic treatment need for the population of eastern Nepal. World J Orthod. 2009 winter; 10(4):311-6.

15. Shrestha BK, Yadav R, Basel P. Prevalence of malocclusion among high school students in Kathmandu valley. Orthodontic Journal of Nepal 2012; 2(1):4-8.

16. Tang EL. Occlusal features of Chinese adults in Hong Kong. Australian Orthodontic Journal 1994; 13(3): 159-63.

17. Lagana G, Masucci C, Fabi F, Bollero P, Cozza P. Prevalence of malocclusions, oral habits and orthodontic treatment need in a 7- to 15- year-old schoolchildren population in Tirana. Progress in Orthodontics 2013; 14: 12.

18. Danaie SM, Asadi Z, Salehi P. Distribution of malocclusion types in 7-9-year-old Iranian children. Eastern Mediterranean Health Journal 2006; 12 (1): 236-40.

19. Baral P. Prevalence of malocclusion in permanent dentition in Aryan and Mongoloid races of Nepal- A Comparative study. Pakistan Orthodontic Journal 2013; 5(2): 57-9.

20. Shrestha S, Shrestha RM. An analysis of malocclusion and occlusal characteristics in Nepalese orthodontic patients. Orthodontic Journal of Nepal June 2013; 3(1): 19-25.

21. Singh VP, Sharma A. Epidemiology of Malocclusion and Assessment of Orthodontic Treatment Need for Nepalese Children. International Scholarly Research Notices 2014; 2014: 4.

22. Farahani $A B$, Farahani $A B$, Eslamipour F. Malocclusion and occlusal traits in an urban Iranian Population. An epidemiological study of 11-to 14-year-old children. European Journal of Orthodontics 2009; 31: 477-84.

23. Arabiun H, Mirzaye M, Nazhvani AD, Ajami S, Faridi S, Bahrpeima F. The prevalence of malocclusion among $14-18$ years old students in Shiraz. J Oral Health Oral Epidemiol 2014; 3(1):8-11.

24. Jamilian A, Darnahal A, Damani E, Talaeipour M, Kamali Z. Prevalence of Orthodontic Treatment Need and Occlusal Traits in Schoolchildren. International Scholarly Research Notices 2014; 2014: 5.

25. Ciuffolo F, Manzoli L, D'Attilio M, Tecco S, Muratore F, Festa F, Romano F. Prevalence and distribution by gender of occlusal characteristics in a sample of Italian secondary school students: a cross sectional study. European Journal of Orthodontics 2005; 27: 601-6.

26. Aikins EA, Onyeaso CO. Prevalence of malocclusion and occlusal traits among adolescents and young adults in Rivers State, Nigeria. Odontostomatol Trop 2014 Mar; 37(145):5-12. 